\title{
Progressive loss of speech output and orofacial dyspraxia associated with frontal lobe hypometabolism
}

\author{
P J Tyrrell, L D Kartsounis, R S J Frackowiak, L J Findley, M N Rossor
}

\begin{abstract}
Three patients are described with slowly progressive loss of speech and dysarthria associated with orofacial dyspraxia, initially with intact written language, who subsequently developed more widespread cognitive abnormalities. Positron emission tomography (PET) revealed bifrontal hypometabolism in all of the patients, most marked in the inferior and lateral portions of both frontal lobes, with some extension into the parietal and temporal cortices in one case. These patients may represent a further example of focal progressive cortical degeneration.
\end{abstract}

Progressive neuropsychological deficits due to focal cortical degeneration have been described by a number of authors. These deficits include dysphasia, ${ }^{1}$ dyspraxia or agnosia, ${ }^{2}$ and cortical blindness. ${ }^{3}$ Most of the cases reported in the literature refer to progressive language related difficulties, some of which eventually progress to more generalised cognitive deterioration. ${ }^{4}$ More generalised cortical degenerations may also present with language difficulties, for example Alzheimer's disease (AD) ${ }^{56}$ Pick's disease, ${ }^{7}$ and the so-called frontal lobe dementias. ${ }^{89}$ Typically, these degenerative disorders are associated with word retrieval difficulties, paraphasias, or dysgraphia. Dysarthria with orofacial dyspraxia has not been generally recognised as a feature of a degenerative dementia, although it may occur in the context of vascular and traumatic lesions of the frontal lobes. Three patients are reported with progressive loss of speech, initially with intact written language, who subsequently developed a more widespread intellectual deficit. All had marked orofacial dyspraxia as an initial presentation. Neuropsychological and PET studies were performed in an attempt to delineate more clearly the neuropsychological and neuroanatomical correlates of this unusual clinical condition.

\section{Case 1}

A 64 year old housewife presented with a three year history of progressive speech production difficulty. One year after the onset of symptoms, her speech was noted to be effortful, with phonemic paraphasic errors, but her repetition of words was relatively satisfactory. Two years later, on assessment before PET scan, her understanding of speech remained well preserved, but her speech expression had deteriorated further. She was dysarthric, and her verbal output was limited to one or two words. In spontaneous writing, she made occasional grammatical errors, and when writing to dictation she transposed or omitted some words. She had marked orofacial apraxia, with an inability to yawn, blow out a match, or blow a kiss on request. When asked to cough, she would only say the word "cough", but was able to do so spontaneously. By contrast, she was able to copy gestures and to mime acts correctly, apart from using the flat of her hand when asked to pretend to comb her hair. Tongue movements were normal, and there were no primitive reflexes. General neurological examination was normal, as was general examination, with a blood pressure of $150 / 90 \mathrm{~mm} \mathrm{Hg}$. All haematological and biochemical investigations were normal, including thyroid function tests. Electroencephalography (EEG) was also normal, but a computerised tomography (CT) scan showed left frontal and anterior temporal atrophy (fig 1).

Neuropsychological assessment was performed on three occasions. In her first assessment (August 1987) on the Wechsler Adult Intelligence Scale (WAIS), ${ }^{10}$ she achieved a verbal IQ of 95 and a performance IQ of 108 . These scores did not suggest any significant degree of general intellectual deterioration, her lower verbal IQ being mainly due to her speech

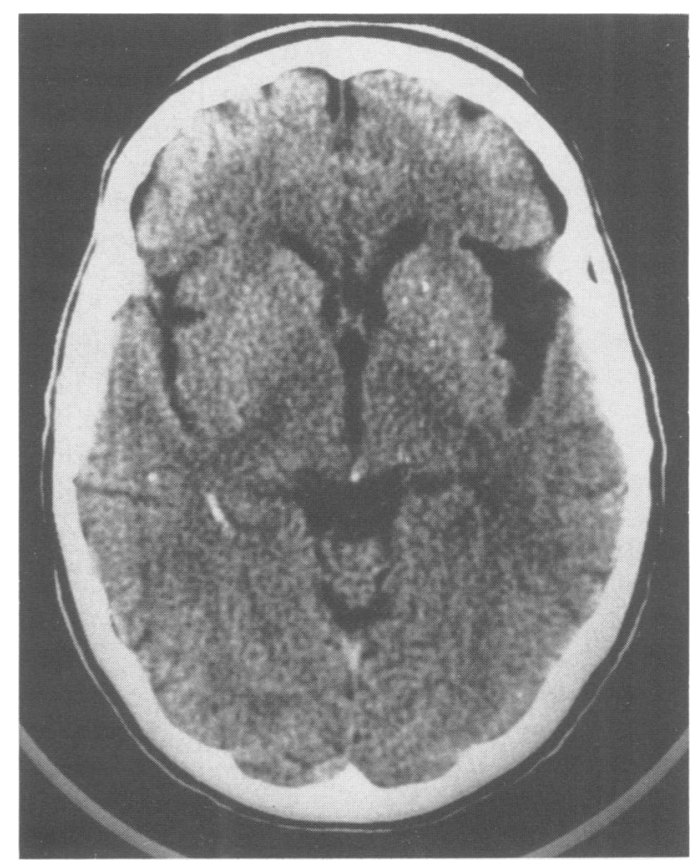

Figure 1 CT head scan of patient 1. The left hand side of the head is seen on the right of the image. 
production difficulties. On the Graded Naming Test ${ }^{11}$ and the Naming from Description Test ${ }^{12}$ she scored $12 / 30$ and $12 / 15$ respectively, suggesting only mild inefficiency on naming tasks. On a spelling test she performed well (Baxter test $\left.^{13}\right)$. Her performance on tests of visual perception and visuospatial function was satisfactory, with a score of $17 / 20$ on the Unusual Views test ${ }^{14}$ and $20 / 20$ on the Dot Centre test. ${ }^{15}$ There was no unequivocal evidence of memory impairment: she named 6/12 Famous Faces and recognised another three (results within normal range for her age group), and achieved a perfect score (30/30) on the "Camden A" Recognition Memory Test comprising coloured photographs (Warrington, personal communication). Although on the longer Recognition Memory Test ${ }^{16}$ her performance was weak, scoring only $34 / 50$ for words and $38 /$ 50 for faces, this appeared to be secondary to attentional factors. On two tests of frontal lobe function she performed satisfactorily: she completed the Weigl's Sorting Task ${ }^{17}$ and her responses on the Cognitive Estimates Test ${ }^{18}$ were within normal limits. On retesting in January 1989, her verbal IQ was 88 and her performance IQ 97 , indicating a relatively mild but significant deterioration since her previous assessment on general ability tests. Despite her speech production difficulties noted earlier her repetition skills continued to be relatively well preserved. Her naming skills were thought to be slightly weaker than previously, scoring $9 /$ 30 on the Graded Naming Test and 13/15 on the Naming from Description Test. There was no suggestion, however, of comprehension difficulties. Her perceptual skills had remained satisfactory, and on this occasion she scored 40/ 50 on both the verbal and visual versions of the Recognition Memory Test, that is within the average range.

In the most recent assessment at the time of PET scanning (July 1989), a further deterioration in her verbal skills was observed. Verbal IQ was now 82, but performance IQ remained at 97 . Consistent with the latter was her average score (6/12) on Advanced Progressive Matrices Set $1 .{ }^{19}$ There appeared to be no significant change in her speech production/articulatory skills since her previous assessment. On the Oldfield Naming Test ${ }^{20}$ she scored $21 / 30$ which was in keeping with her previous performance on the Graded Naming Test. Word comprehension ability appeared to be well preserved, with a score of $134 / 150$ on the British Picture Vocabulary Scale. ${ }^{21}$ On the Unusual Views test of visual perception she scored 20/20. She achieved an average score on the verbal part of the Recognition Memory Test (42/50) but on the visual part she performed below the fifth percentile $(35 / 50)$, apparently due to lapses in concentration. Thus on a shorter visual recognition memory test comprising coloured photographs of buildings (Warrington, personal communication) she obtained a perfect score $(25 / 25)$.

In summary, over a period of two years her verbal skills had deteriorated significantly and there was also evidence of a mild decline in her nonverbal reasoning skills. Her memory and perceptual functions were generally well preserved. Her speech continued to be effortful and dysarthric with phonemic paraphasic errors. Word comprehension and literacy skills had remained intact, but there was evidence of mild word retrieval difficulties.

\section{Case 2}

A 65 year old right handed retired engineering technician presented with a six year history of speech disturbance. The initial symptoms had been a reduction in verbal output, with stuttering, although his writing remained normal. $\mathrm{He}$ had a past history of exertional angina, but no other history of note. There was no family history of dementia or other neurological illness. Eighteen months after the onset of symptoms, he had non-fluent, dysarthric speech, with evidence of orofacial dyspraxia. Verbal comprehension and confrontational naming were excellent (allowance was made for his impaired speech production). Spontaneous writing was good, with appropriate sentence construction and choice of vocabulary. His symptoms progressed, however, and when assessed before PET scan, was described by his family as having been mute for three years. Verbal comprehension remained wellpreserved, but his writing was dysgraphic, and agrammatic. In addition, his non-verbal communication seemed to be impaired, with lack of eye contact, and difficulty in understanding gestures. He had marked orofacial dyspraxia, and was unable to cough, yawn or blow a kiss on command; tongue movements were slightly slow. He was able to cough spontaneously. In contrast, he was able to copy hand gestures, and perform transitive and intransitive mimes. Pout and snout reflexes were present, and he demonstrated "magnetic" behaviour with forced utilisation. General and neurological examination was otherwise normal, with a blood pressure of $110 / 60 \mathrm{~mm}$ mercury. All haematological and biochemical investigations were normal, including thyroid function tests. His CSF was acellular with a total protein content of $0.88 \mathrm{~g} / \mathrm{l}$, the syphilis serology was negative, and no oligoclonal bands were detected. EEG was normal, but a CT scan showed frontal and anterior temporal atrophy (fig 2).

Neuropsychological testing was carried out on two occasions, four years apart. On first assessment (November 1984), he achieved a performance IQ of 123 . He could comply with the demands of only three verbal subtests of the scale because of his speech production deficit, but on all of them he scored within the average range or above. On the verbal and visual versions of the Recognition Memory Test, he performed at a bright average level or above (Words 48/50 correct, Faces 44/50), and on the Unusual Views test of visual perception he scored 20/20. As noted above he presented with severe speech production deficit. He had difficulty with the repetition of single words, and his repetition of single phonemes was particularly impaired. By contrast, his naming to confrontation and word comprehension skills were very well preserved, scoring $27 / 30$ on the Graded Naming Test and $145 / 150$ on 
Figure 2 CT head scan of patient 2. The left hand side of the head is seen on the right of the image.

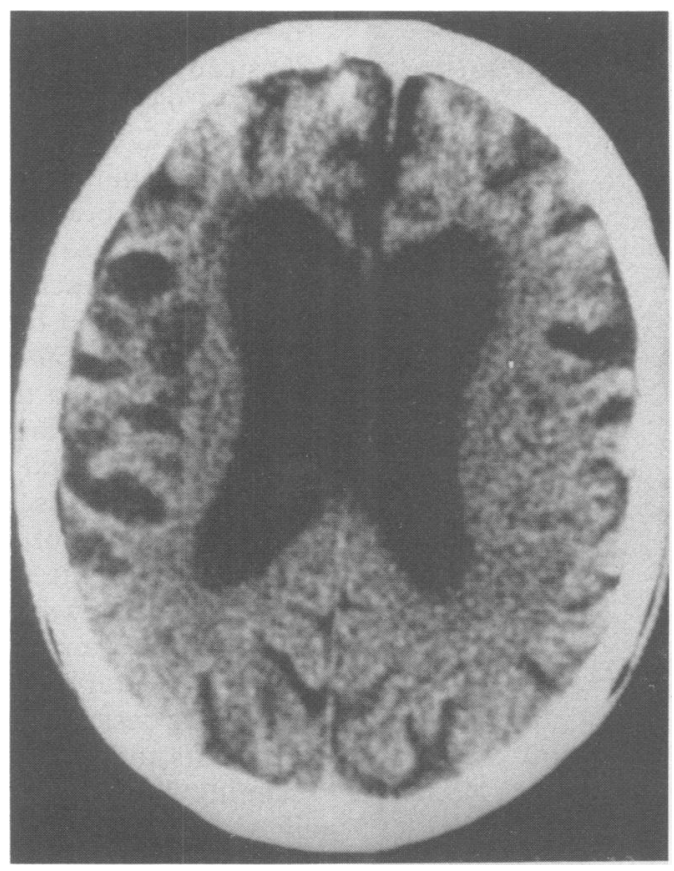

the Peabody Picture Vocabulary Test. ${ }^{22}$ His writing was satisfactory with appropriate syntax and vocabulary.

On retesting before the PET scan (September 1988), he was mute. He had great difficulty initiating action and focusing attention, and his responses tended to be perseverative. On Raven's Coloured Progressive Matrices ${ }^{23}$ he scored at the sixtieth percentile, that is, at a level equivalent to an IQ of 104. Similarly, on the Block Design subtest of the WAIS he scored at an average level. He identified correctly by pointing 14/15 Famous Faces. ${ }^{24}$ On the Fragmented Letters test of visual perception ${ }^{25}$ and the Dot Centre visuospatial test he scored $13 / 14$ and $7 / 7$ respectively. $\mathrm{He}$ copied drawings adequately. Although mute, he scored at least within the bright average range $(121 / 127)$ on the Peabody Picture Vocabulary Test. His writing, however, suggested both motor and spelling dysgraphia deficits. He was able to carry out relatively simple written additions and subtractions, but had difficulty with more complex ones.

In summary, the patient's speech production difficulties had deteriorated over four years to such an extent that he had become mute. He showed marked orofacial apraxia, and had difficulty initiating action and focusing attention. He had dysgraphia and dyscalculia, and his reasoning skills had significantly weakened. Word comprehension and memory functions, however, appeared well preserved, and there was no unequivocal evidence of perceptual or constructional difficulties.

\section{Case 3}

A 65 year old retired bank messenger presented with a three year history of difficulty in speaking and swallowing. He took early retirement one year before the onset of symptoms, and his wife attributed this to his inability to continue with his work after a bereavement in the family. The symptoms may have started after a social occasion when he had had to meet some of his ex-colleagues: his wife noticed that he had been extremely anxious about the occasion beforehand. On his return home, his speech was slurred for the first time, despite having drunk very little alcohol, and it did not return to normal. His speech progressively deteriorated, although until one year before presentation, he was able to communicate effectively by means of written messages. Soon after the onset of the speech disturbance, he also complained of swallowing difficulties, particularly for liquids. There was no nasal regurgitation. He continued to drive a car without getting lost, and recognised familiar faces without difficulty. On first assessment six months before the PET scan, and again four months later, his speech was hypophonic and dysarthric. Verbal comprehension appeared to be somewhat impaired, although he was able to follow a three stage command. Orofacial dyspraxia was present, with inability to cough, yawn, or blow a kiss on command, although he was able to cough spontaneously. In addition, he was unable to hold his breath, despite understanding the instruction. Dyspraxia of the limbs was also noted, with inability to copy some relatively complex hand movements, and use of body parts while miming. The rest of the neurological examination was normal, with no muscle wasting or fasciculation, normal symmetrical reflexes, and flexor plantar responses. General examination was also normal, with a blood pressure of $150 / 90 \mathrm{~mm} \mathrm{Hg}$. On later assessment, at the time of the PET scan, there had been further deterioration of his speech, which was barely intelligible. Grasp, pout and snout reflexes were now present, with a brisk jaw-jerk. Swallowing water induced choking. On general neurological examination, muscles were noted to be generally wasted, and he had developed scattered fasciculation and extensor plantar responses. Limb tone and power were normal, and reflexes symmetrical. Haematological and biochemical investigations were normal as was CSF examination, with negative syphilis serology. EEG, CT head scan (fig 3) and carotid angiography were all normal. Electromyography showed fasciculation with fibrillation, and sharp waves in upper and lower limbs, consistent with anterior horn cell disease.

Neuropsychological assessment was performed on two occasions, six months apart. His score on the National Adult Reading Test ${ }^{26}$ suggested a premorbid IQ of 105 . In his first assessment, he achieved a verbal IQ of 71, and a performance IQ of 87. His score on Raven's Coloured Progressive Matrices was at the twenty fifth percentile. These results indicated a general intellectual deterioration, particularly with verbal tests. His articulatory impairment appeared to be a specific deficit in producing the basic sounds of speech correctly by making distortions of target phonemes. However, on the Oldfield and Graded Naming Tests he scored $20 / 30$ and $10 / 30$ respectively, suggesting only mild word retrieval difficulties, and on the Peabody Picture Vocabulary Test scored at 
Figure 3 CT head scan of patient 3. The left hand side of the head is seen on the right of the image.

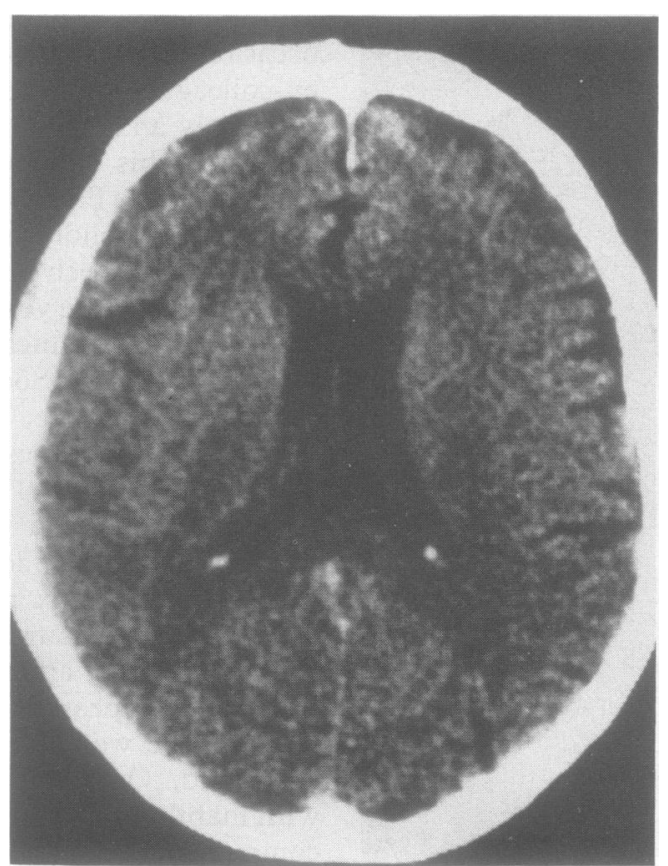

a level equivalent to an IQ of 77. His spelling on the Baxter test was within the normal range. His recall of major events was satisfactory, but on two recognition memory tests comprising coloured photographs (Warrington, personal communication) he scored at a defective level (Camden A: 24/30, Camden B 14/30). His bimanual hand coordination was poor, and he had difficulty completing the Weigl's Sorting Test. Visual perception appeared normal as he scored 19/20 on the Fragmented Letters Test. Thus at this stage he had a marked speech production deficit with only mild word retrieval difficulties per se, in the context of general intellectual deterioration; there was evidence of impairment on some memory tests but his visual perceptual skills were intact. He was reassessed six months later, at the time of the PET scan. He attempted to talk, but could only produce undifferentiated sounds. His writing ability was impaired, with spelling errors and occasional neologisms. On the British Picture Vocabulary Test, he scored only $44 / 60$, that is, below the first percentile. On the verbal and visual versions of the Recognition Memory Test he performed below normal limits (Words $37 / 50$, Faces $23 / 50$ ), although he was able to identify 10/15 Famous Faces. His performance IQ on the WAIS had deteriorated to 67 , and his score on the Raven's Coloured Progressive Matrices was now below the fifth percentile. Tests of visual perception also showed impairment, with a dull average score on the Objects Silhouettes test of visual perception, and a defective level score on the animals version of this test. ${ }^{27}$ Qualitative aspects of his behaviour during testing suggested a tendency to perseveration, which appeared to have affected his performance on certain tests. In summary, the patient's ability to communicate verbally had become very severely impaired, and his comprehension and writing skills had also become very limited. His language deficits were mirrored by a further deterioration in his reasoning skills.

\section{Methods}

${ }^{15} \mathrm{O}$ steady state PET scans were performed on the CTI/931/12/8 (CTI, Tenn, USA) scanner at the MRC Cyclotron Unit at the Hammersmith Hospital, to obtain regional values of $\mathrm{CMRO}_{2}$ (cerebral metabolic rate for oxygen). The performance characteristics of this scanner have been described. ${ }^{28}$ Ethical approval for these studies, and for normal studies on eight volunteers (aged 59-83) mean age 69.25 years, was obtained from the Ethical Committees of St Mary's, the National and Hammersmith Hospitals. Approval for administering radiolabelled gases was obtained from ARSAC (Administration of Radioactive Substances Advisory Committee of the United Kingdom). Written consent was obtained from all patients, and normal volunteers, after a full explanation of the procedure. The details of the control groups are described elsewhere. ${ }^{29}$

Patients and subjects were positioned on the scanning bed, with the head symmetrically aligned along the orbitomeatal line, resting in an individually made rigid polyurethane foam head mould. Careful observation of the patients and subjects throughout the scan ensured that there was no significant head movement. A 22 gauge plastic cannula was inserted into the radial artery at the wrist, after subcutaneous infiltration of long acting local anaesthetic (bapivicaine 1\%). After a 15 minute transmission scan $\left(\mathrm{Ge}^{68} \mathrm{Ga}^{68}\right)$, two consecutive emission scans were performed during inhalation of $\mathrm{C}^{15} \mathrm{O}_{2}$, and ${ }^{15} \mathrm{O}_{2}$, respectively, at steady state, with a ten minute wash-out period between each scan. Finally, a further six minute scan following four minutes of $\mathrm{C}^{15} \mathrm{O}$ inhalation, and equilibration for one minute, was collected. The emission scans were transformed into parametric images after correction for attenuation, using the arterial oxygen content and whole blood and plasma activities, measured in triplicate, during $\mathrm{C}^{15} \mathrm{O}_{2}$, ${ }^{15} \mathrm{O}_{2}$, and $\mathrm{C}^{15} \mathrm{O}$ scanning. Thus four quantitative data sets of $\mathrm{CMRO}_{2}, \mathrm{CBF}$ (cerebral blood flow), and OER (oxygen extraction ratio), and cerebral blood volume (CBV) were obtained. Details of this method, and the cerebral blood volume component, have been described previously..$^{30-32}$

Images were inspected to ascertain the presence and position of the focal deficits. Images were presented as 15 planes of data with a resolution of $8.5 \times 8.5 \times 7 \mathrm{~mm}$ after reconstruction, with no interplane deadspace. Images were also inspected in the coronal and sagittal planes following a 1:3 linear interpolation in the vertical axis (z-plane), thus generating 43 images. Scans were analysed on a computer (Sun 3/60) with image analysis software (ANALYZE:BRU/Mayo Clinic), which allows scans to be displayed relative to the intercommissural line (AC-PC line). ${ }^{33}$ This permitted anatomical localisation using standard stereotactic coordinates based on the Talairach atlas. ${ }^{34}$

Numerical data were obtained using a circular region of interest of diameter $8 \mathrm{~mm}$ (approximately one resolution element), which covered the visible cortical ribbon. In each 
Table This shows the CMRO, values for each of the patients for each of the anatomical areas sampled, on both sides of the brain. Mean (SD) values for the normal population, are also given. Patient values marked with an asterix (*) are outside the $95 \%$ confidence interval

\begin{tabular}{|c|c|c|c|c|c|c|c|c|c|c|}
\hline & \multicolumn{4}{|c|}{ Normal Subjects ( $n=8)$} & \multicolumn{2}{|c|}{ Patient 1} & \multicolumn{2}{|c|}{ Patient 2} & \multicolumn{2}{|c|}{ Patient 3} \\
\hline & Left & $(s d)$ & Right & $(s d)$ & Left & Right & Left & Right & Left & Right \\
\hline Cingulate Gyrus & $2 \cdot 88$ & $(0 \cdot 41)$ & $2 \cdot 91$ & $(0.44)$ & 2.06 & $2 \cdot 44$ & $2 \cdot 29$ & 2.09 & $2 \cdot 01^{\star}$ & 2.54 \\
\hline Anterior Frontal Gyrus (F1) & $2 \cdot 92$ & $(0.27)$ & $2 \cdot 96$ & $(0.36)$ & $1.96^{\star}$ & $2 \cdot 18^{\star}$ & $2 \cdot 12^{\star}$ & $1 \cdot 88^{\star}$ & $2 \cdot 03^{\star}$ & $1.98^{\star}$ \\
\hline Middle Frontal Gyrus (F2) & $2 \cdot 66$ & $(0.31)$ & 2.66 & $(0 \cdot 31)$ & $1.73^{\star}$ & $2 \cdot 3$ & 1.94 * & $1.55^{\star}$ & $2 \cdot 03$ & $2 \cdot 17$ \\
\hline Posterior Frontal Gyrus (F3) & $2 \cdot 67$ & $(0 \cdot 37)$ & $2 \cdot 73$ & $(0 \cdot 37)$ & $0.96^{\star}$ & 2.39 & $1 \cdot 38^{\star}$ & $.73^{\star}$ & $1 \cdot 62^{\star}$ & $1.90^{\star}$ \\
\hline Superior Temporal Gyrus (T1) & $2 \cdot 74$ & $(0 \cdot 40)$ & 2.76 & $(0.41)$ & $2 \cdot 31$ & 2.57 & $2 \cdot 22$ & $1.51^{\star}$ & $2 \cdot 45$ & 2.63 \\
\hline Middle Temporal Gyrus (T2) & $2 \cdot 78$ & $(0.42)$ & $2 \cdot 79$ & $(0 \cdot 42)$ & $2 \cdot 51$ & $2 \cdot 49$ & $2 \cdot 26$ & $1 \cdot 67^{\star}$ & $2 \cdot 35$ & 2.73 \\
\hline Inferior Temporal Gyrus (T3) & $2 \cdot 81$ & $(0 \cdot 40)$ & $2 \cdot 82$ & $(0 \cdot 42)$ & $2 \cdot 61$ & $2 \cdot 88$ & $2 \cdot 34$ & $2 \cdot 09$ & $2 \cdot 58$ & $2 \cdot 33$ \\
\hline Anterior Parietal Cortex & $2 \cdot 82$ & $(0 \cdot 42)$ & $2 \cdot 83$ & $(0.41)$ & 2.04 & $2 \cdot 36$ & $2 \cdot 46$ & $1 \cdot 83^{\star}$ & $2 \cdot 46$ & 2.57 \\
\hline Posterior Parietal Cortex & $2 \cdot 85$ & $(0 \cdot 40)$ & $2 \cdot 85$ & $(0 \cdot 4)$ & 2.53 & $2 \cdot 73$ & $2 \cdot 22$ & $1 \cdot 44^{\star}$ & $2 \cdot 42$ & 2.99 \\
\hline Occipital Cortex & $3 \cdot 49$ & $(0.62)$ & $3 \cdot 43$ & $(0.61)$ & $2 \cdot 76$ & $2 \cdot 96$ & $2 \cdot 70$ & $2 \cdot 74$ & $4 \cdot 02$ & $3 \cdot 37$ \\
\hline Cerebellum & $3 \cdot 72$ & $(0 \cdot 43)$ & $3 \cdot 64$ & $(0.55)$ & $2 \cdot 90$ & 2.93 & $2 \cdot 86$ & $2 \cdot 82$ & $4 \cdot 37$ & 3.92 \\
\hline Thalamus & $3 \cdot 47$ & $(0.58)$ & $3 \cdot 49$ & $(0.61)$ & $2 \cdot 39$ & $2 \cdot 69$ & $2 \cdot 98$ & $2 \cdot 44$ & $1 \cdot 89^{\star}$ & $3 \cdot 27$ \\
\hline Caudate Nucleus & 3.55 & $(0.63)$ & 3.58 & $(0.62)$ & $3 \cdot 38$ & 3.07 & 3.69 & 2.59 & $1.93^{\star}$ & $3 \cdot 43$ \\
\hline Putamen & 3.52 & $(0.66)$ & 3.54 & $(0 \cdot 65)$ & $2 \cdot 60$ & $3 \cdot 14$ & $3 \cdot 46$ & $2 \cdot 41$ & $2 \cdot 79$ & $2 \cdot 87$ \\
\hline
\end{tabular}

Values marked ${ }^{\star}$ are outside $95 \%$ confidence interval, that is $p<0.05$

case, there was direct cross-referencing to the anatomical coordinate system. Visual inspection indicated that the areas of maximal hypometabolism were restricted to frontal, temporal and parietal lobes. Regions of interest were therefore placed on the anterior, middle, and posterior frontal gyri (labelled F1, F2, and F3), the cingulate gyrus, the superior, middle and inferior temporal gyri (labelled T1, T2, and $\mathrm{T} 3$ ), and anterior and posterior parietal areas in the right and left hemispheres. Readings were taken from those scan planes which corresponded exactly to the anatomical reference planes, according to the distance of the plane from the AC-PC line. This meant that each structure was sampled by nine regions of interest from nine adjacent anatomical planes. The value for the given structure is presented as the mean of the number of regions of interest. In addition, cerebellar cortex was sampled from the lowest two atlas planes, occipital cortex from four planes, and subcortical structures (thalamus, head of caudate and putamen) on each of three representative planes. Measurements were made from the left and right hemispheres independently.

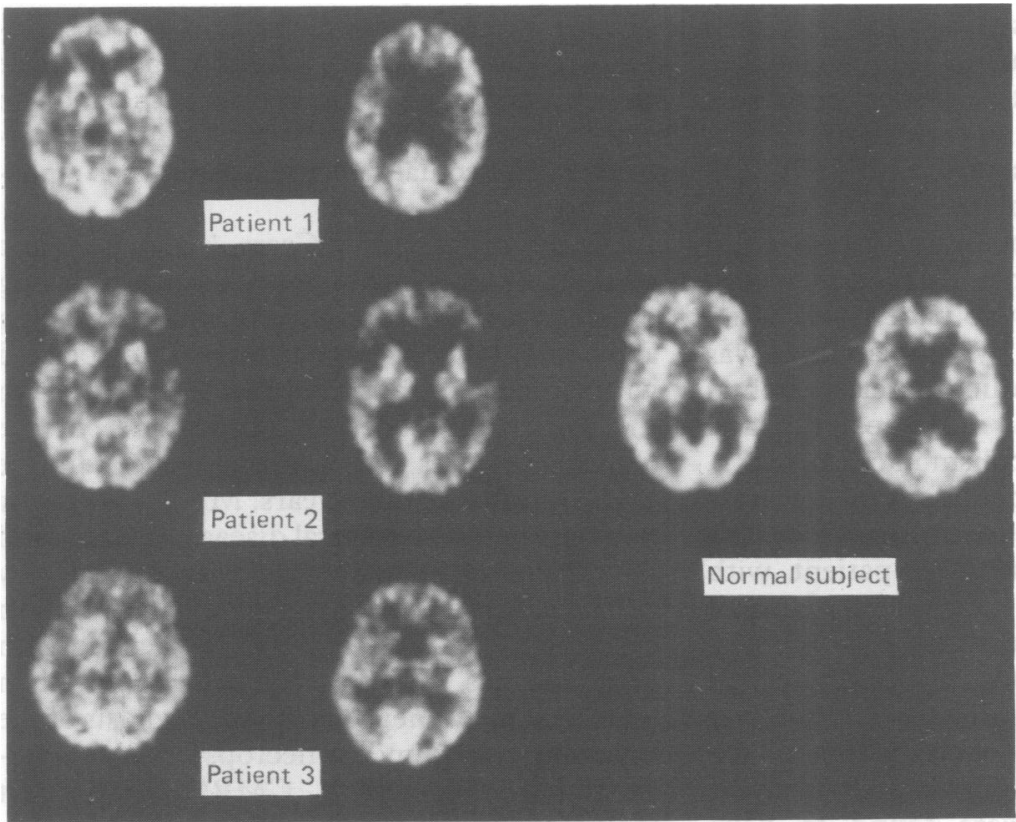

Figure 4 Representative $\mathrm{CMRO}_{2}$ scans from all three patients, with a normal for comparison. All images are scaled to their own maximum, so no colour scale can be shown. The images are sliced parallel to the AC-PC line (see text); the left hand image cuts through the thalami, the right hand image is approximately $1 \mathrm{~cm}$ above.

\section{Results}

$\mathrm{CMRO}_{2}$ results for the three patients, and the eight normal volunteers, are shown in the table.

$\mathrm{CMRO}_{2}$ was matched in all regions with $\mathrm{CBF}$, with a normal OER. Scans from all patients, with a normal for comparison, are shown in fig 4. Regional $\mathrm{CMRO}_{2}$ values are illustrated graphically in fig 5 .

The results show a profound reduction in frontal lobe metabolism in all cases, affecting particularly the inferior and middle frontal gyri on both sides. In Case 2 , where there was a longer history and the most severe symptoms, there was also extension into the parietal and temporal lobes on the right. Cases 1 and 3 had cortical hypometabolism restricted to both frontal lobes, particularly to the posterior frontal gyrus. In Case 3, low metabolism was also found in the left thalamus and left caudate nucleus, while metabolism in the putamen appeared to be normal.

\section{Discussion}

The association of loss of speech output and orofacial dyspraxia with frontal lobe lesions, affecting particularly the inferior and lateral portions of the frontal lobes, is in keeping with data from studies of patients with vascular lesions that have implicated the left inferior frontal lobe in the articulation of speech. ${ }^{35}$ Orofacial dyspraxia appears to be a frequent accompaniment of these lesions. A number of cases of dysarthria associated with orofacial dyspraxia due to missile injury to the left frontoparietal region, were described by Nathan, ${ }^{36}$ who used the term "cortical dysarthria" to describe loss of speech output in the presence of relatively preserved written language in these cases. Recently, three patients with permanent mutism, but completely intact written language and gestural communication, two due to trauma, and one due to bilateral vascular lesions, have been reported. ${ }^{37}$ In all cases, orofacial apraxia was also a very prominent feature, and CT scans showed bilateral low density lesions in the fronto-temporal lobes. The authors suggest that bilateral frontal dysfunction is necessary for permanent mutism with orofacial apraxia. This inference agrees with the PET data presented here.

Although the underlying aetiology in our three cases is unknown, the slowly progressive 

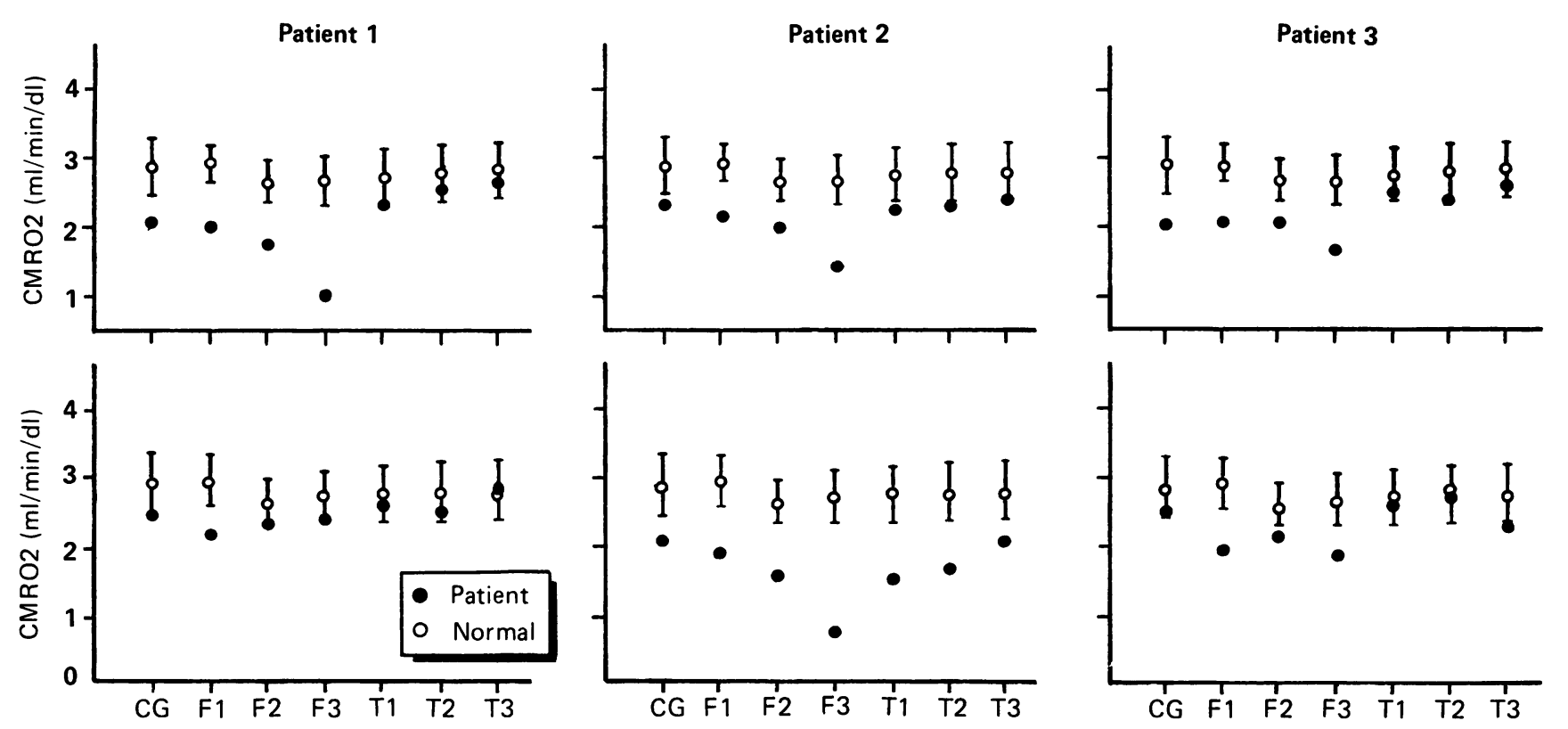

Figure 5 Illustrates the $\mathrm{CMRO}_{2}$ results in graphical format. The CMRO, value is given on the y-axis (ml/min/dl), and the figures on the $x$-axis represent different areas sampled. $C G=$ cingulate gyrus, F1, 2, 3 the three frontal gyri, and T1, 2, 3 the three temporal gyri. The graphs on the upper row represent left hemisphere values; on the lower row, right hemisphere values.

history in normotensive patients, and the absence of vascular lesions on CT scan, make a degenerative aetiology likely. In all these patients, the deficits had initially been limited to speech production, in the absence of any other specific language impairment. However, all the patients had deteriorated before scanning, so that widespread but not global, intellectual deterioration was present. These cases therefore seem to represent a slowly progressive cognitive disorder, apparently arising from a focal cortical degeneration, and eventually progressing to a more generalised intellectual deterioration.

Focal cortical degeneration has been described as a cause of progressive dysphasia, ${ }^{1}$ apraxia, agnosia, ${ }^{2}$ and visual agnosia. ${ }^{3}$ Progressive loss of speech output with orofacial dyspraxia due to a degenerative cortical process of the frontal lobe has not previously been described. Rossor et al (paper submitted) described frontal lobe hypometabolism in association with progressive upper limb dyspraxia and gait disturbance, but in their three cases speech was not affected. In the two patients who had PET scans, frontal lobe hypometabolism was most marked in the midline anterior frontal region, in contrast to the more posterior and lateral frontal hypometabolism in our cases.

The underlying histopathology in progressive focal cortical degeneration may be heterogeneous. One case of a patient with progressive aphasia who subsequently became demented was found at necropsy to have Pick's disease, ${ }^{3839}$ another had the pathological features of Alzheimer's disease, ${ }^{40}$ while yet another had Creutzfeldt-Jakob disease. ${ }^{41}$ Two further cases, who had aphasia without more generalised dementia, were found to have spongiform change localised to the left frontotemporal region. ${ }^{42}$

Frontal lobe hypometabolism has been reported in dementia of the frontal lobe type $^{849}$ and in Pick's disease. ${ }^{44}$ Dysphasia is reported in Pick's disease, but not in isolation from other cognitive abnormalities or personality change. ${ }^{7}$ Of the frontal lobe dementias, in the series reported by Gustafson ${ }^{8}$ all the patients developed language abnormalities, but these were limited to stereotyped phrases, echolalia, verbal mannerisms and confabulation, rather than speech production abnormalities. Similarly, and unlike our patients, in the seven frontal lobe dementia cases reported by Neary et al, ${ }^{9}$ speech production deficits per se were not a prominent early feature, although reduction in verbal output with stereotyped phrases and paraphasias occurred later in the disease. None of our cases fit the classic descriptions of Pick's disease, ${ }^{7}$ although the presence of progressive frontal hypometabolism associated with the development of more widespread intellectual deficits raises this as a possibility.

Case 3 differs from Cases 1 and 2 in two respects, namely the prominent swallowing difficulty and the presence of muscle wasting and fasciculation. Dysphagia may be associated with unilateral or bifrontal lobe lesions, ${ }^{45}$ and in this patient preceded the appearance of the clinical features of motor neuron disease (MND) by some three years. MND may rarely be associated with cortical disease, and a frontal lobe dementia characterised pathologically by neuronal loss and spongiform change has been described. ${ }^{46} 47$ case of MND associated with dementia has recently also been reported in which extensive neuronal loss and gliosis of the thalamus was found at necropsy. ${ }^{48}$ It is noteworthy that in case $3, \mathrm{CMRO}_{2}$ in the left thalamus and left caudate nucleus was low; this patient had a three year history of orofacial dyspraxia with anterior horn cell features occurring only very late in the disease. The 
underlying histology in our patients remains unknown and compared with reported necropsy cases of focal cortical degeneration ${ }^{39}$ ${ }^{42}$ may be heterogenous. These cases, however, present a clinically recognisable syndrome which seems to represent a further example of focal cortical degeneration.

We are indebted to Drs $F$ Clegg and $M$ Jackson of the Department of Neuropsychology, The National Hospital, for performing assessments in two of these patients, to Professor E $\mathrm{K}$ Warrington for helpful advice, and to Professor P K Thomas
and Dr M Ron of the National Hospital for permission to study
one of their patients. We are also extremely grateful to the Staff of one of their patients. We are also extremely grateful to the Staff of the Chemistry and Physics sections of the MRC Cyclotron Unit, particularly Miss Claire Taylor and Mr Graham Lewington, study was partly supported by an MRC project grant.

1 Mesulam M-M. Slowly progressive aphasia without generalised dementia. Ann Neurol 1982;11:592-8.

2 De Renzi E. Slowly progressive visual agnosia or apraxia without dementia. Cortex 1986;22:171-80.

3 Benson DF, Davis RJ, Snyder BD. Posterior cortical atrophy. Arch Neurol 1988;45:789-93.

4 Poeck K, Luzzatti C. Slowly progressive aphasia in three patients: the problem of accompanying neuropsychological deficit. Brain 1988;111:151-68

5 Kirshner HS, Webb WG, Kelly MP, Wells CE. Language Disturbance: an initial symptom of Cortical Degenerations and Dementia. Arch Neurol 1984;41:491-6.

6 Selnes OA, Carson K, Rovner B, Gordon B. Language Disturbance as an Initial Symptom of Cortical Degenerations and Dementia. Arch Neurol 1988;41:491-6.

7 Tissot R, Constandinidis RJ. Pick's disease. In: Fredriks JAM, ed. Handbook of clinical neurology 2 (46). Elsevier, BV 1985.

8 Gustafson L. Frontal lobe degeneration of non-Alzheimer type II. Clinical picture and differential diagnosis. Arch Gerontol Geriatr 1987;6:209-23.

9 Neary D, Snowden JS, Northen B, Goulding P. Dementia of frontal lobe type. J Neurol Neurosurg Psychiatry 1988; 51:353-61.

10 Wechsler D. Wechsler Adult Intelligence Scale. The Psychological Corporation: New York, 1955.

11 McKenna P, Warrington EK. Graded Naming Test. Windsor, UK: NFER-Nelson, 1983.

12 Coughlan AK, Warrington EK. Word comprehension and word retrieval in patients with localised cerebral lesions. Brain 1978;101:163-85.

13 Baxter D. Acquired Spelling Disorders. PhD Thesis: University of London, 1987.

14 Warrington EK, Taylor A. The contribution of the right temporal lobe to object recognition. Cortex 1973;9: 152-64.

15 Warrington EK, James $M$. Visual apperceptive agnosia: a clinico-anatomical study of three cases. Cortex

16 Warrington EK. Recognition Memory Test. Windsor, UK: NFER-Nelson Publishing, 1984.

17 Weigle E. On the psychology of the so-called process of abstraction. Journal of Abnormal and Social Psychology 1941;36:3-33.

18 Shallice T, Evans ME. The involvement of the frontal lobes in cognitive estimation. Cortex 1978;XIV:294-303.

19 Raven JC. Advanced progressive matrices. London: HK Lewis, 1958.

20 Oldfield RC, Wingfield A. Response latencies in naming objects. Quart J Exp Psychol 1965;18(4):273-81.

21 Dunn LM, Dunn LM, Whetton C, Pintille D. British Picture Vocabulary Scale. Windsor, UK: NFER-Nelson, 1982.
22 Dunn LM. Peabody Picture Vocabulary Test. Minnesota: AGS, 1965

23 Raven JC, Court JH, Raven J. Coloured Progressive Matrices. London: HK Lewis, 1977.

24 Warrington EK, McCarthy RA. The fractionation of retrograde amnesia. Brain and Cognition 1988;7:184-200

25 Warrington EK, James $M$. Disorders of visual perception in patients with localised cerebral lesions. Neuropsychologia 1967;5:253-66.

26 Nelson HE. The National Adult Reading Test. Windsor, UK NFER-Nelson, 1982.

27 Warrington EK, James M. Visual Object Recognition in patients with right hemisphere lesions: axes or features? Perception 1986;15:355-66.

28 Spinks T, Guzzardi R, Bellina CR. Performance characteristics of a whole body positron tomograph. J Nucl Med 1988;29:1833-41.

29 Tyrrell PJ, Warrington EK, Frackowiak RSJ, Rossor MN Heterogeneity in progressive aphasia due to focal cortical atrophy: a clinical and PET scan study. Brain 1990;113:1321-6.

30 Frackiowiak RSJ, Lenzi G-L, Jones T, Heather JD. Quantitative measurement of regional cerebral blood flow and oxygen metabolism in man using ${ }^{15} \mathrm{O}$ and positron emis sion tomography: theory, procedure, and normal values. Cereb Blood Flow and Metab 1980;4:727-36.

31 Lammertsma AA, Jones T. Correction for the presence of intravascular oxygen-15 in the steady state technique for measuring regional oxygen extraction ratio in the brain: description of the method. J Cereb Blood Flow and Metab 1983;3:416-24.

32 Lammertsma AA, Wise RJS, Heather JD, et al. Correction for the presence of intravascular oxygen-15 in the steadystate technique for measuring regional oxygen extraction ratio in the brain: 2 results in normal subjects and brain tumour and stroke patients. J Cereb Blood Flow and Metab 1983;3:425-31.

33 Friston K, Passiongham RE, Nutt $\mathrm{J}$, et al. Localisation in PET images: direct fitting of the intercommissural (AC PC) line. J Cereb Blood Flow and Metab 1989;9:690-5.

34 Talairach J, Szikla G, Tournoux P, et al. Atlas d'anatomie stereotaxique du telencephale. Paris: Masson et Cie, 1967.

35 Mohr JP, Pessin MS, Finkelstein S, Funkenstein HH, Duncan GW, Davis KR. Broca aphasia: pathologic and clinical. Neurology 1975;28:311-24.

36 Nathan P. Facial apraxia and apraxic dysarthria. Brain 1947;LXX:449-78.

37 Grosswasser Z, Korn C, Grosswasser-Reider I, Solzi P. Mutism associated with buccofacial apraxia and bihemisMutism associated with buccofacial apraxia and bihemi
pheric lesions. Brain and Language 1988;34:157-68.

38 Wechsler AF. Presenile dementia presenting as aphasia. $J$ Neurol Neurosurg Psychiatry 1977;40:303-5.

39 Wechsler AF, Verity A, Rosenschein S, Fried I, Scheibel AB. Pick's Disease: a clinical, computed tomographic and histological study with Golgi impregnation observations. Arch Neurol 1982;39:287-90

40 Pogacar S, Williams RS. Alzheimer's disease presenting as slowly progressive aphasia. Rhode Is Med J 1984;67: $181-5$

41 Mandell AM, Alexander MP, Carpenter S. CreutzfeldtJakob disease presenting as isolated aphasia. Neurology 1989;39:55-8.

42 Kirshner HS, Tanridag O, Thurman L, Whetsell WO Progressive Aphasia without dementia: two cases with focal spongiform degeneration. Ann Neurol 1989;22: 527-32.

43 Risberg J. Frontal lobe degeneration of non-Alzheimer type. III. Regional cerebral blood flow. Arch Gerontol Geriatr 1987;6:225-33.

44 Kamo H, McGeer PL, Harrop R, et al. Positron emission tomography and histopathology in Pick's disease. Neurology 1987;37:439-45.

45 Meadows JC. Dysphagia in unilateral cerebral lesions. $J$ Neurol Neurosurg Psychiatry 1973;36:853-60.

46 Mitsuyima Y, Takamiya S. Presenile dementia with motor neuron disease in Japan. Arc Neurol 1979;36:592-3.

47 Wikstrom J, Pactau A, Palo J, Sulkava R, Haltia M. Classic amyotrophic lateral sclerosis with dementia. Arch Neurol 1982;39:681-3

48 Deymeer F, Smith TW, De Gilrolami U, Drachmann DA. Thalamic dementia motor neurone disease. Neurology 1989;39:58-61. 